\title{
A problemática dos organismos geneticamente modificados e a formação científica do cidadão comum: um estudo com alunos de escolas portuguesas
}

\section{The genetically modified organisms issue and citizens' science education: a study with students of Portuguese schools}

\author{
Luís Dourado ${ }^{1} \quad$ Luís Matos ${ }^{2}$
}

\begin{abstract}
Resumo: A sociedade atual depara-se com assuntos mediáticos e controversos, de raiz científica, de que é exemplo a problemática sobre os organismos geneticamente modificados (OGM). Estes organismos são, para uns, uma mais-valia e, para outros, algo perigoso, o que tem motivado um debate a nível científico, político e económico, do qual os cidadãos não se devem abster. Para tal, estes indivíduos devem ser pessoas informadas, responsáveis e ativas, aspetos para os quais contribui a formação em ciências. A investigação realizada centrou-se na problemática dos OGMs e envolveu a aplicação de um questionário a 175 alunos de escolas portuguesas sobre as suas concepções e opiniões em relação aos OGM. Este estudo demonstrou que a maioria dos alunos tem ideias vagas, nem sempre cientificamente corretas, sobre o tema, e que não rejeita os OGMs, apesar de não ter muitas certezas em relação à utilização dos mesmos.
\end{abstract}

Palavras-chave: Organismos geneticamente modificados. OGM. Educação em ciências.

Abstract: Contemporary society has been faced with some scientific issues. Genetically Modified Organis$\mathrm{ms}(\mathrm{GMO})$ is an example of such issues. For some people, these organisms have an added value. For others, they are taken as a threat. The existence of these two opposite reactions has led to a debate in which citizens should engage, as they are an interested party to it. However, to do so, citizens should be scientifically informed, responsible and active people. Science education can contribute to them developing such competences. The research carried out was focused on student's ideas regarding GMO. 175 students attending Portuguese schools answered to a questionnaire about their conceptions and opinions regarding to GMO. The results of the former study suggest that students hold some scientifically incorrect ideas on GMO, and that they do not completely reject GMO even though they show some doubts about the use of GMO.

Keywords: Genetically modified organisms. GMO. Science education.

\footnotetext{
${ }^{1}$ Instituto de Educação, Universidade do Minho, 4710-057, Campus de Gualtar, Braga, Portugal. E-mail: ldourado@ie.uminho.pt

${ }^{2}$ Escola Básica 2,3, Paço de Sousa, Portugal.
} 


\section{Introdução}

Os organismos geneticamente modificados (OGMs) estão cada vez mais presentes na vida das pessoas. Se, por um lado, a utilização destes organismos pode trazer vantagens, a mesma utilização também levanta dúvidas, pelo menos ao nível do senso comum, em termos ambientais e de saúde pública. Assim, a produção e utilização dos OGMs continuam a ser tema polémico e mediático, sobre o qual o cidadão comum deve ter formação científica básica, para compreender o fenómeno e ter uma posição responsável em relação a ele.

Nas escolas portuguesas, ao nível do Ensino Básico, este assunto apenas é abordado na disciplina de Ciências Naturais do $9^{\circ}$ ano. Reconhecendo a importância das ideias dos alunos sobre o tema, apresentamos um artigo que resulta de um dos estudos realizados para a nossa tese de mestrado, intitulada 'a problemática dos organismos geneticamente modificados e a formação científica do cidadão comum: um estudo com manuais escolares e alunos do $9^{\circ}$ ano do concelho de Penafiel', no qual caracterizamos as concepções e opiniões dos alunos que frequentam escolas públicas portuguesas, no final do Ensino Básico, relativamente aos OGMs.

\section{A educação em ciências no Ensino Básico em Portugal e a formação científica do cidadão comum}

Segundo Matthews (2009), a educação em ciências é um fator que condiciona a construção da cosmovisão dos indivíduos. A educação em ciências deve contribuir para a existência de alunos com conhecimentos científicos conceptuais, mas, também, com competências que lhes permitam a tomada de decisões no quotidiano (MATTHEWS, 2009), em que frequentemente os meios de comunicação social fazem referência a assuntos sociocientíficos controversos (REIS, 2008). Estes aspetos são considerados no documento 'Currículo nacional do Ensino Básico - competências essenciais’ do Ministério da Educação, nomeadamente quando se refere que os alunos devem, no final do Ensino Básico, ser capazes de mobilizar o conhecimento, para compreender a sua realidade e para abordar problemas do quotidiano (PORTUGAL, 2001a); e também no documento "Orientações curriculares de ciências físicas e naturais", do mesmo ministério, quando se refere que os alunos devem ter oportunidade de refletir sobre algumas das aplicações do conhecimento científico, nomeadamente na área da genética, e sobre as suas implicações (PORTUGAL, 2001b). Este último documento dá ainda a entender que a discussão de notícias de natureza sociocientífica veiculadas na comunicação social pode contribuir para a concretização daqueles propósitos.

De acordo com Cachapuz, Praia e Jorge (2004), a educação em ciências deve formar cidadãos cientificamente cultos, dotados de conhecimentos científicos, mas, também, de opiniões, valores e competências que lhes permitam participar ativamente e responsavelmente em sociedades modernas que se querem abertas e democráticas. No mesmo sentido, segundo Reis (2008), a ideia de um cidadão passivo, governado por outros, deve ser substituída pela ideia de cidadão ativo, capaz de intervir nos processos de decisão com que se depara.

Assim, a escola deve munir os seus alunos de capacidades básicas que lhes permitam refletir sobre a informação que recebem quotidianamente, e elaborar as suas próprias conclu- 
sões, contribuindo, assim, para que o cidadão comum seja capaz de se situar nas questões sóciocientíficas, em geral, e de lidar com o fenómeno dos OGMs e das suas implicações no mundo atual, em particular.

\section{Os organismos geneticamente modificados e suas implicações}

Desde a antiguidade que o Homem tem selecionado plantas e animais com as características mais desejáveis, procurando preservar essa característica por meio do cruzamento e seleção tradicionais (BORÉM; SANTOS; BOWEN, 2003; VARZAKAS; ARVANITOYANNIS; BALTAS, 2007), alterando o património genético daqueles organismos (FUNDACIÓN COTEC, 2006).

Varzakas, Arvanitoyannise Baltas (2007) referem que a engenharia genética, ao tornar possível a manipulação da informação genética dos organismos, levou ao aparecimento de organismos geneticamente modificados (OGM). De acordo com estes autores, um OGM é um organismo cujo material genético foi modificado de um modo não natural, o qual, segundo o disposto em Fundación COTEC (2006), pode ter características diferentes das iniciais.

Segundo Borém, Santos e Bowen. (2003), a variedade destes organismos é cada vez maior e as suas utilizações cada vez mais amplas, nomeadamente a nível agropecuário, ambiental, alimentar, de saúde e industrial, de que são exemplos, respetivamente: a resistência a pragas e tolerância aos herbicidas; a biorremediação dos solos e da água; o maior valor nutricional dos alimentos; a produção de novos produtos farmacêuticos e industriais.

Fernandez-Cornejo e Caswell (2006) fazem referência à existência de três gerações de OGMs, de acordo com as suas finalidades: uma primeira geração em que a variedade geneticamente modificada (GM) apresenta características reforçadas em relação à variedade nãoGM, de que são exemplos variedades GM de milho tolerantes a determinados herbicidas ou resistentes a determinadas pragas; uma segunda geração em que os OGMs têm um maior valor nutricional do que a variedade não-GM, de que é exemplo o 'arroz dourado', uma variedade GM de arroz que tem uma quantidade maior de vitamina A; uma terceira geração em que os OGMs produzem fármacos ou sintetizam novos produtos, de que é exemplo a produção de insulina humana por bactérias transgénicas.

Porém, o recurso aos OGMs tem sido polémica e não está isenta de eventuais riscos, quer a nível ambiental, quer a nível da saúde, de que são exemplo as possíveis implicações na redução da biodiversidade, ou no aparecimento de alergias (VARZAKAS; ARVANITOYANNIS; BALTAS, 2007).

Wynne (2001) defende a importância de clarificar o que é o risco objetivo (risco que pode ser medido estatisticamente) e o que é o risco subjetivo (incerteza de um acontecimento, consoante ele é analisado pelo indivíduo) para o debate e a aceitação dos OGMs, uma vez que é uma temática de grande envolvimento emocional e pessoal.

$\mathrm{Na}$ análise da relação risco/benefício, deve-se ainda comparar o impacto produzido pelo OGM, com o impacto produzido pela variedade não-GM (SEHNAL; DROBNÍK, 2009).

Investigações feitas acerca dos possíveis perigos na utilização de OGMs têm revelado que apesar dos possíveis impactos negativos, não se têm registado graves impactos ambientais ou de saúde associados à utilização da engenharia genética em culturas agrícolas nos Estados Unidos (VARZAKAS; ARVANITOYANNIS; BALTAS, 2007). 
Contudo, Varzakas, Arvanitoyannis e Baltas (2007) reconhecem que a biotecnologia comporta alguns riscos, incertezas e receios, e que, apesar de não se terem comprovado aqueles receios, muitos pensam que as consequências negativas do uso de OGMs poderão aparecer a longo prazo, nomeadamente: o desenvolvimento de alergias e a contaminação de variedades não-GM, a redução da biodiversidade, a excessiva dependência de poucas variedades de culturas.

Segundo o disposto em Fundación COTEC (2006), todos os OGMs aprovados pelas entidades competentes têm equivalência sustentável, isto é, têm as mesmas características e propriedades do seu correspondente não-GM, exceto em relação à característica introduzida por engenharia genética, e são tão seguros quanto ele. No mesmo documento, acrescentase que nunca se estudaram tão intensamente alimentos como os OGMs e que a própria organização mundial de saúde (OMS) manifestou que os OGMs em comercialização não apresentavam risco maior do que o seu correspondente não-GM.

Apesar de toda a polémica em relação aos OGMs, na última década, registou-se um rápido e contínuo crescimento na utilização da tecnologia dos OGMs, que se repercute tanto em termos de área plantada como no número de países a fazê-lo (WINHAM, 2009).

A este propósito, James (2008) refere que, em 2008, havia 25 países produtores de OGMs nos cinco continentes, sendo que os maiores produtores eram quatro países da América (EUA, Argentina, Brasil, Canadá), a China e a Índia. O mesmo autor refere que, em 2008, a cultura GM dominante era a soja, ocupando 53\% de toda a área cultivada com OGMs, depois o milho (30\% da área cultivada) e o algodão (12\% da área cultivada), e que a tolerância aos herbicidas era a principal característica dos OGMs cultivados.

Ainda de acordo com James (2008), os OGMs e as suas aplicações tinham, em 2008, um valor de mercado a nível mundial de 7,5 biliões de dólares, o que terá levado a um maior investimento de muitas empresas na área da biotecnologia.

\section{Concepções e ideias dos alunos sobre OGMs}

Sobre as concepções e opiniões de alunos sobre os OGMs, vários estudos foram já efetuados em diversos países, tendo nós encontrado os seguintes: Chern e Rickertsen, (2001); Corazza-Nunes et al. (2007); Dawson (2007); Firmino (2007); Klop e Severiens (2007); Pedrancini et al. (2007); Pedrancini et al. (2008); Prokop et al. (2007); Santos (2006); Usak et al. (2009); Sáez; Niño; Carretero (2008).

$\mathrm{Da}$ análise destes estudos e no que diz respeito às concepções dos alunos sobre OGMs, os aspetos que consideramos mais relevantes são:

. existe desigualdade no grau de informação em relação aos OGMs, entre alunos de diferentes países (CHERN; RICKERTSEN, 2001);

- a maioria dos alunos tem pouca compreensão científica dos conceitos relacionados com os OGMs (CORAZZA-NUNES et al., 2007; DAWSON, 2007; PEDRANCINI et al., 2007; PROKOP et al., 2007; PEDRANCINI et al. 2008). Para além disso, os conhecimentos demonstrados pelos alunos são, muitas vezes, generalistas e idênticos aos divulgados pela comunicação social (CORAZZA-NUNES et al., 2007; PEDRANCINI et al., 2007; PEDRANCINI et al. 2008); 
. os alunos demonstraram ter conhecimentos mais consistentes em relação às aplicações da biotecnologia, nomeadamente nos domínios da saúde/medicina, do que em relação aos princípios básicos da biotecnologia (USAK et al., 2009);

- verifica-se a existência de concepções alternativas em relação aos OGMs, de que são exemplo: 'os OGMs contêm substâncias químicas perigosas' (PROKOP et al., 2007; USAK et al., 2009), ou a ideia de que os OGMs e os transgénicos são conceitos iguais (CORAZZANUNES et al., 2007; PEDRANCINI et al., 2007).

Quanto às opiniões dos alunos sobre organismos geneticamente modificados identificadas naqueles estudos, os aspetos que consideramos mais relevantes são:

- a opinião dos alunos em relação aos OGMs varia consoante o estudo efetuado. Assim, podemos referir como exemplos o estudo de Sáez, Niño e Carretero (2008), em que os alunos têm maioritariamente uma opinião positiva em relação aos OGMs; o de Prokop et al. (2007), em que a maioria dos alunos mostra relutância em relação a estes organismos, e o de Chern e Rickertsen (2001), em que há alguma equidade na distribuição de frequências.

. de um modo geral, quanto maior o conhecimento dos alunos em biotecnologia, mais positiva é a sua opinião em relação aos seus produtos e processos (CORAZZA-NUNES et al., 2007; KLOP; SEVERIENS, 2007; PROKOP et al., 2007; USAK et al., 2009);

. a opinião perante a biotecnologia depende de fatores cognitivos, afetivos e comportamentais (KLOP; SEVERIENS, 2007);

. a opinião dos alunos depende do tipo de OGM (DAWSON, 2007), da sua finalidade e garantias dadas (CHERN; RICKERTSEN, 2001; KLOP; SEVERIENS, 2007);

- a maioria dos alunos demonstra receio e cautela em relação aos riscos dos OGMs e a possíveis problemas associados à utilização de alimentos transgénicos pelo Homem (DAWSON, 2007; FIRMINO, 2007).

\section{Metodologia}

\section{População e amostra}

A população corresponde ao universo dos alunos que frequentam o $9^{\circ}$ ano de escolaridade em escolas públicas portuguesas.

O nosso estudo envolveu 175 alunos que frequentavam o $9^{\circ}$ ano de escolaridade em escolas públicas portuguesas. Destes alunos, 89\% tinham 14-15 anos e 11\% tinham 16-17 anos; $56 \%$ eram do sexo feminino e $44 \%$ do sexo masculino; $93 \%$ estavam a frequentar o $9^{\circ}$ ano pela primeira vez.

\section{Técnica e instrumento de recolha de dados}

A recolha de dados relativamente às concepções e opiniões dos alunos sobre os OGMs foi feita por meio da técnica de inquérito, a qual, segundo McMillan e Schumacher (2006), permite obter informação sobre conhecimentos, crenças, opiniões, comportamentos e ideias de uma amostra. A opção pelo inquérito por questionário teve a ver, também, com a rápida e fácil obtenção de um grande número de dados. 
O instrumento de recolha de dados foi um questionário, tipo teste de conhecimentos, construído pelo investigador e sujeito a validação de conteúdo (GALL; GALL; BORG, 2003; MCMILLAN; SCHUMACHER, 2006) por especialistas em educação em ciências.

A validação do questionário foi necessária para nos certificarmos que as informações que o mesmo permite recolher são as necessárias ao nosso estudo e que as mesmas estão de acordo com as ideias dos alunos (DE KETELE; ROEGIERS, 1993).

$\mathrm{Na}$ validação do questionário, assegurou-se que o questionário era adequado à amostra e aos objetivos do estudo, através da aplicação de um pré-teste, após validação de conteúdo, a um grupo de alunos com características idênticas aos alunos da amostra.

Construiu-se, assim, um questionário para detectar concepções e opiniões dos alunos em relação aos OGMs.

Os alunos não se identificaram no questionário, tendo apenas referido o sexo, a idade e se estavam a frequentar o $9^{\circ}$ ano pela primeira vez, ou não. Assim, asseguramos a privacidade dos alunos e a confidencialidade dos dados (MCMILLAN; SCHUMACHER, 2006).

\section{Recolha de dados}

O questionário foi aplicado em contexto de sala de aula, pois, segundo De Ketele e Roegiers (1993), o questionário deve ser aplicado na situação mais natural possível.

O professor-aplicador dos questionários foi contatado pelo investigador, ao qual foi exigido que não prestasse qualquer auxílio relativamente às respostas dos alunos e que não permitisse a troca de ideias entre os alunos, de modo a garantir a igualdade na recolha de dados e a fiabilidade dos resultados obtidos (DE KETELE; ROEGIERS, 1993).

\section{Tratamento de dados}

O questionário utilizado na recolha de dados foi constituído por questões de escolha múltipla, em que se exigia a fundamentação da escolha, e por questões de resposta aberta.

No tratamento e análise de dados, agrupamos as respostas em categorias de resposta de modo a se obter uma representação simplificada das respostas dos alunos (BARDIN, 2004). Deste modo, em relação às questões de escolha múltipla, as categorias de resposta foram definidas a priori e eram iguais às respostas possíveis; nas questões de resposta aberta, as categorias foram definidas após uma análise geral do conteúdo das respostas e segundo os requisitos enunciados por Bardin (2004).

Para cada questão, determinou-se a prevalência relativa das diferentes categorias de resposta, utilizando-se, para o efeito, a frequência absoluta e relativa de cada uma. As frequências absolutas e relativas de cada categoria de resposta foram comparadas com as das restantes categorias da mesma resposta. 


\section{Resultados e discussão}

\section{Concepções dos alunos em relação aos organismos geneticamente modificados}

Ao analisarmos as respostas dos alunos, constatámos que 97,7\% dos alunos já tinham ouvido falar em OGMs. Este facto já era esperado pois, antes da aplicação dos questionários em cada turma, certificámo-nos de que o assunto havia já sido lecionado nas aulas.

Aliás, a sala de aula foi a resposta mais frequente quando se perguntou aos alunos em que contextos tiveram contato com os OGMs: $96,5 \%$ dos alunos deram essa resposta, a qual não deve ser dissociada da resposta 'manual escolar' (referido por $84,8 \%$ dos alunos), o que vem de encontro às ideias de Santos (2001) quando refere a importância que o manual tem no processo de ensino e aprendizagem.

Em relação a outros contextos em que os alunos ouviram falar em OGMs, a frequência relativa de cada um é, por ordem decrescente: televisão (42,1\% dos alunos), internet $(35,7 \%$ dos alunos), jornais ( $23,4 \%$ dos alunos), revistas $(17,0 \%$ dos alunos), filmes $(16,4 \%$ dos alunos), publicidade ( $10,5 \%$ dos alunos) e rádio ( $4,1 \%$ dos alunos). Deste modo, não se deve excluir a influência destes meios na aprendizagem desta temática, aspeto que remete para as ideias de Cachapuz, Praia e Jorge (2004) quando defendem a utilização de informações veiculadas pelos meios de comunicação social durante o ensino formal das ciências.

$\mathrm{Na}$ Tabela 1 apresentamos o conceito de OGM dado pelos alunos.

Tabela 1. Conceito de OGM

\begin{tabular}{|c|c|c|}
\hline \multirow[b]{2}{*}{ Categoria } & \multicolumn{2}{|c|}{ Alunos $(n=171)$} \\
\hline & $\mathbf{f}$ & $\%$ \\
\hline Um OGM é um organismo cuja informação genética foi modificada & 88 & 51,4 \\
\hline Um OGM é um organismo modificado & 48 & 27,0 \\
\hline Um OGM é um organismo ao qual foi acrescentado ou retirado um gene & 15 & 8,7 \\
\hline Um OGM é um clone & 9 & 5,3 \\
\hline Um OGM é um organismo não natural & 3 & 1,8 \\
\hline Um OGM é um transgénico & 2 & 1,2 \\
\hline Outro & 4 & 2,3 \\
\hline Não responde & 2 & 1,2 \\
\hline
\end{tabular}

Fonte: Elaborado pelos autores.

De acordo com os resultados da Tabela 1, verifica-se que a categoria de resposta cientificamente correta e adequada a este nível de ensino é a mais frequente. Esta categoria de resposta está próxima do conceito referido por Varzakas, Arvanitoyannis e Baltas (2007), ou seja, um OGM é um organismo cujo material genético foi modificado de um modo não natural.

Quanto às restantes categorias, salientamos que, somando as respostas em que os alunos referem que um OGM é um transgénico $(1,2 \%)$ com as respostas das categorias 'organismos aos quais foi acrescentado ou retirado um gene' $(8,7 \%)$ e 'organismos aos quais foi adicionado um ou mais elementos de outro organismo' $(2,3 \%)$, onde nos parece haver aproximação ao conceito de transgénico adequado a este nível de ensino - organismo cuja infor- 
mação genética foi alterada por ter recebido um ou mais genes de outro(s) organismo(s) (CORAZZA-NUNES et al., 2007) - teríamos uma categoria de resposta com uma frequência relativa de $12,2 \%$, o que seria a terceira categoria de resposta mais frequente.

De igual modo salientamos que 5,3\% dos alunos associaram OGM a Clone.

Ainda em relação ao conceito de OGM, o facto de quase metade dos alunos (48,6\%) não ter apresentado a definição correta de OGM vai de encontro aos estudos de CorazzaNunes et al. (2007), Dawson (2007), Firmino (2007); Pedrancini et al. (2007), Pedrancini et al. (2008), Prokop et al. (2007), Santos (2006), quando referem que a compreensão científica dos conceitos relacionados com os OGMs é escassa. Segundo Usak et al. (2009), o desconhecimento em relação a conceitos da biotecnologia e a existência de ideias alternativas devem-se à falta de espaço no currículo de biologia para o ensino da genética.

No que diz respeito aos exemplos de OGMs conhecidos dos alunos, que referiram já ter ouvido falar de OGMs, há uma grande variedade. Assim, optamos por dividi-los por grupos: um para plantas/frutos, outro para animais, e outro para os restantes organismos.

Em relação às plantas/frutos, os exemplos mais frequentes são: o milho (referido por $24,6 \%$ dos alunos), o 'arroz dourado' (9,4\% dos alunos) e o tomate (8,8\% dos alunos).

Estes exemplos surgem em manuais escolares e estão parcialmente de acordo com os resultados obtidos nos estudos de Corazza-Nunes et al. (2007), de Pedrancini et al. (2008) e de Santos (2006), quando referem que os exemplos de OGMs mais conhecidos dos alunos são a soja e o milho.

Quanto aos exemplos de animais GMs, os mais frequentes são: o frango ( $9,4 \%$ dos alunos) e o porco (6,4\% dos alunos), os quais surgem em manuais escolares. Constatamos também que o número de exemplos de animais GM é menor do que o de plantas GM.

Salientamos ainda a resposta 'Ovelha' (5,3\% dos alunos), a qual pode resultar de uma associação com a ovelha 'Dolly' e as respostas 'Copy Cat' e 'Snuppy' (ambos clones e referidos por 1,2\% dos alunos, cada). O conjunto destas respostas atinge uma frequência de 7,7\% e permite pensar que alguns dos alunos associam o conceito de OGM ao de clone, tal como foi já referido, a propósito do conceito de OGM.

Relativamente a outros exemplos de OGMs, apenas há referência a 'microrganismos' $(1,2 \%$ dos alunos - dois alunos), apesar de os mesmos serem referidos em manuais escolares.

\section{Opiniões dos alunos em relação aos organismos geneticamente modificados}

No que diz respeito às opiniões dos alunos em relação aos OGMs, confrontamos os alunos com a compra de um OGM de tipo alimentar (óleo alimentar produzido a partir de soja GM) e um OGM de tipo não alimentar (T-shirt feita com fibras de algodão GM).

Em relação à compra de óleo alimentar contendo soja GM verifica-se que a resposta mais frequente é 'talvez' (45,0\% dos alunos). Quanto aos alunos que assumem uma decisão, a frequência dos alunos que não comprariam aquele alimento ( $36,9 \%$ dos alunos) é cerca do dobro daqueles que o comprariam (18,1\% dos alunos).

Quanto à fundamentação dada pelos alunos que comprariam este tipo de óleo alimentar, apresentamos a Tabela 2. 
Tabela 2. Fundamentação dos alunos que afirmaram que comprariam óleo de soja GM

\begin{tabular}{lrr}
\hline \multicolumn{1}{c}{ Categoria } & \multicolumn{2}{c}{ Alunos (n= 31) } \\
\cline { 2 - 3 } & $\mathbf{f}$ & \% \\
\hline Os OGMs são tão seguros como os não-GM & 7 & 22,6 \\
Os alimentos GM são melhores do que os não-GM & 4 & 12,9 \\
A compra do óleo não depende, diretamente, da existência do OGM & 3 & 9,7 \\
O alimento tem um ingrediente GM & 2 & 6,5 \\
Atualmente, quase todos os produtos têm ingredientes GM & 2 & 6,5 \\
Fundamentação não relacionada & 11 & 35,5 \\
Não responde & 2 & 6,5 \\
\hline
\end{tabular}

Fonte: Elaborado pelos autores.

De acordo com os dados da Tabela 2, verifica-se que a categoria de resposta mais frequente é a de que os OGMs são tão seguros como os não-GM, seguida da categoria que considera os alimentos GM melhores do que os não-GM. Esta resposta está de acordo com um dos resultados de Corazza-Nunes et al. (2007) e de Pedrancini et al. (2007) em que os alunos referiram que uma das vantagens dos OGMs é a melhoria nutricional dos alimentos.

As demais categorias de resposta remetem a decisão da compra para outros aspetos que não as propriedades do OGM.

Em relação à fundamentação dada pelos alunos que talvez comprassem o óleo, apresentamos a Tabela 3.

Tabela 3. Fundamentação dos alunos que afirmaram talvez comprar óleo alimentar com soja GM

\begin{tabular}{lrr}
\hline \multicolumn{1}{c}{ Categoria } & \multicolumn{2}{c}{ Alunos (n= 77) } \\
\cline { 2 - 3 } & $\mathbf{f}$ & \% \\
\hline Os OGMs podem ser perigosos para a saúde & 32 & 41,6 \\
Os OGMs têm vantagens e desvantagens & 8 & 10,4 \\
A compra do óleo não depende, diretamente, da existência do OGM & 8 & 10,4 \\
O alimento tem um ingrediente GM & 7 & 9,1 \\
Os OGMs são tão seguros como os não-GM & 5 & 6,5 \\
Os OGMs não são naturais & 3 & 3,9 \\
Os OGMs são melhores do que os não-GM & 1 & 1,3 \\
Atualmente, quase todos os produtos têm ingredientes GM & 1 & 1,3 \\
Fundamentação não relacionada & 9 & 11,7 \\
Não responde & 3 & 3,9 \\
\hline
\end{tabular}

Fonte: Elaborado pelos autores.

De acordo com os dados da Tabela 3, verifica-se que a categoria de resposta mais frequente é a de que os OGMs podem ser perigosos para a saúde, a qual pode ser exemplificada pela resposta 'este OGM pode causar o aparecimento de novas doenças'.

$\mathrm{Na}$ segunda categoria de resposta mais frequente, considera-se que os OGMs têm vantagens e desvantagens, o que é exemplificado pela resposta 'os OGMs têm vantagens e desvantagens: aumento da produtividade, redução dos riscos; desvantagens: podem causar novas doenças, novos vírus'. 
Nas restantes categorias de resposta, para além das categorias, 'os OGMs são tão seguros como os não-GM' (6,5\%), ou 'os OGMs são melhores do que os não-GM' (1,3\%), as quais são fundamentações não coerentes com a resposta dada, as demais categorias não estão relacionadas com as propriedades do OGM, havendo uma (os OGMs não são naturais) $(3,9 \%)$ que remete para princípios éticos dos alunos.

Relativamente à fundamentação dada pelos alunos que não comprariam o óleo, apresentamos a Tabela 4.

Tabela 4. Fundamentação dos alunos que afirmaram que não comprariam óleo alimentar de soja GM

\begin{tabular}{lcc}
\hline \multicolumn{1}{c}{ Categoria } & \multicolumn{2}{c}{ Alunos $(\mathbf{n = 6 3 )}$} \\
\cline { 2 - 3 } & $\mathbf{f}$ & $\mathbf{\%}$ \\
\hline Os OGMs são perigosos & 21 & 33,3 \\
O alimento tem um ingrediente GM & 17 & 27,0 \\
Os OGMs não são naturais & 13 & 20,6 \\
Fundamentação não relacionada & 12 & 19,0 \\
\hline
\end{tabular}

Fonte: Elaborado pelos autores.

Com base na Tabela 4, verifica-se que a categoria de resposta mais frequente é a de que os OGMs são perigosos. Esta resposta foi dada por 33,3\% daqueles alunos (21 alunos). Destes 21 alunos, 12 alunos referiram que os OGMs podem ser perigosos para a saúde; três alunos disseram que os OGMs são perigosos, mas não especificam por quê; dois alunos defenderam que não há certezas em relação à segurança dos OGMs; dois alunos disseram que podem ser perigosos para a saúde e para o ambiente; dois alunos referiram que os OGMs podem ter produtos tóxicos perigosos.

As restantes categorias de resposta que fundamentam a não-compra daquele óleo alimentar não estão diretamente relacionadas com as propriedades do OGM.

Em relação à compra de uma t-shirt fabricada com fibras de algodão GM verificase que a resposta mais dada é 'sim' (42,7\% dos alunos). Quanto aos outros alunos, 42,1\% referiram que talvez comprassem aquela t-shirt e 14,6\% que não a comprariam.

Estes resultados evidenciam que há uma maior receptividade à t-shirt com algodão GM do que ao óleo alimentar com soja GM, o que demonstra que houve alunos que mudaram de opinião, de acordo com o tipo de OGM em causa.

$\mathrm{Na}$ Tabela 5, apresentamos a fundamentação dada por aqueles que comprariam a tshirt.

Perante os resultados evidenciados na Tabela 5, verifica-se que a categoria de resposta mais frequente é a de que os OGMs são tão seguros como os não-GM.

A segunda categoria de resposta mais frequente foi a de que a compra da t-shirt não está relacionada com o OGM, mas com outros fatores, como o preço ou a estética, o que vai de encontro a um dos resultados do estudo de Klop e Severiens (2007), quando referem que a opinião perante a biotecnologia depende de fatores cognitivos, afetivos e comportamentais.

$\mathrm{Na}$ terceira categoria de resposta mais frequente, $12,3 \%$ daqueles alunos referem que os OGMs são melhores que os organismos não-GM. 
Tabela 5. Fundamentação dos alunos que comprariam uma t-shirt fabricada com algodão GM

\begin{tabular}{lrr}
\hline \multicolumn{1}{c}{ Categoria } & \multicolumn{2}{c}{ Alunos $(\mathbf{n = 7 3 )}$} \\
\cline { 2 - 3 } & \multicolumn{1}{c}{$\mathbf{f}$} & $\%$ \\
\hline Os OGMs são tão seguros como os não-GM & 26 & 35,6 \\
A compra da t-shirt dependeria de outros fatores que não o OGM & 24 & 32,9 \\
Os OGMs são melhores do que os correspondentes não-GM & 9 & 12,3 \\
Esta t-shirt tem um constituinte GM & 2 & 2,7 \\
Os OGMs podem ser perigosos para a saúde & 1 & 1,4 \\
A t-shirt não é alimento & 1 & 1,4 \\
Os OGMs têm vantagens e desvantagens & 1 & 1,4 \\
Atualmente, quase todos os produtos têm ingredientes GM & 1 & 1,4 \\
Não sabe/ Não responde & 8 & 11,0 \\
\hline
\end{tabular}

Fonte: Elaborado pelos autores.

Nas restantes categorias, realçamos o facto de um aluno ter dito que os OGMs podem ser perigosos para a saúde e de outro aluno ter reconhecido que os OGMs têm vantagens e riscos. Estas fundamentações podem ser consideradas pouco coerentes com a decisão tomada.

Na Tabela 6, registramos a fundamentação daqueles que talvez comprassem a t-shirt.

Tabela 6. Fundamentação dos alunos que talvez comprassem uma t-shirt fabricada com algodão GM

\begin{tabular}{lrr}
\multicolumn{1}{c}{ Categoria } & \multicolumn{2}{c}{ Alunos (n= 72) } \\
\cline { 2 - 3 } & $\mathbf{f}$ & \% \\
\hline A compra dependeria de outros fatores que não o OGM & 19 & 26,4 \\
Os OGMs podem ser perigosos & 13 & 18,1 \\
Não há certeza em relação à segurança no consumo dos OGMs & 7 & 9,7 \\
Os OGMs são iguais aos não-GM & 5 & 6,9 \\
Esta t-shirt tem um ingrediente GM & 4 & 5,6 \\
A t-shirt não é alimento & 4 & 5,6 \\
Os OGMs têm vantagens e desvantagens & 3 & 4,2 \\
Os OGMs são melhores do que as variedades não-GM & 2 & 2,8 \\
Os OGMs não são naturais & 2 & 2,8 \\
Atualmente, quase todos os produtos têm ingredientes GM & 1 & 1,4 \\
Não relacionada & 5 & 6,9 \\
Não sabe/ Não responde & 7 & 9,7 \\
\end{tabular}

Fonte: Elaborado pelos autores.

Dos resultados verificados na Tabela 6, a categoria de resposta mais frequente é a de que a compra daquele produto não está diretamente relacionada com o OGM, mas com outros fatores, como o preço, o conforto ou a estética do produto, o que, mais uma vez, está de acordo com um dos resultados do estudo de Klop e Severiens (2007), quando dizem que a opinião sobre a biotecnologia depende de fatores cognitivos, afetivos e comportamentais.

A segunda categoria de resposta mais frequente é a de que os OGMs podem ser perigosos. Dos 13 alunos que deram respostas desta categoria, 11 alunos referiram que os OGMs podem ser perigosos para a saúde, enquanto os outros dois alunos não especificaram quais seriam os perigos. 
Nas restantes categorias de resposta, destacamos as que dizem que os OGMs são iguais aos não-GM e que os OGMs são melhores do que os não-GMs, por serem fundamentações incoerentes com a opção tomada; bem como a categoria de resposta 'a t-shirt não é um alimento’ por distinguir OGMs de tipo alimentar de OGMs de tipo não alimentar.

$\mathrm{Na}$ Tabela 7, apresentamos os resultados relativos à fundamentação dada pelos alunos que não comprariam a t-shirt.

Tabela 7. Fundamentação dos alunos que não comprariam uma t-shirt fabricada com algodão GM

\begin{tabular}{lrr}
\hline \multicolumn{1}{c}{ Categoria } & \multicolumn{2}{c}{ Alunos $(\mathbf{n = 2 5})$} \\
\cline { 2 - 3 } & $\mathbf{f}$ & \% \\
\hline Os OGMs podem ser perigosos & 7 & 28,0 \\
Esta t-shirt tem um ingrediente GM & 6 & 24,0 \\
A compra da t-shirt dependeria de outros fatores que não o OGM & 4 & 16,0 \\
Os OGMs não são naturais & 2 & 8,0 \\
Não relacionada & 6 & 24,0 \\
\hline
\end{tabular}

Fonte: Elaborado pelos autores.

Analisando a Tabela 7, vemos que a categoria mais comum é a de que os OGMs podem ser perigosos. Dos sete alunos que deram resposta desta categoria, seis referiram que os OGMs podem ser perigosos para a saúde; o outro aluno não especificou a sua resposta.

Nas restantes categorias de resposta, os alunos usam fundamentações que não estão relacionadas com as propriedades do OGM. Destes, dois alunos fazem referência a questões de natureza ética ao considerarem que os OGMs não são naturais.

Fazendo uma síntese em relação à compra do óleo de soja GM e da t-shirt com algodão GM, verifica-se que os resultados se aproximam dos verificados nos estudos de Chern e Rickertsen (2001), Corazza-Nunes et al. (2007); Firmino, (2007); Pedrancini et al. (2007); Pedrancini et al. (2008); Sáez, Niño e Carretero (2008); Santos (2006), quando referem que apesar de a maioria dos alunos não rejeitar os OGMs, muitos têm reservas em relação à sua utilização. Constata-se, ainda, que o OGM de tipo não alimentar é mais aceito do que o de tipo alimentar.

Os possíveis riscos considerados pelos alunos estão de acordo com outros estudos, nomeadamente quando referem riscos na saúde (CORAZZA-NUNES et al., 2007; PEDRANCINI et al., 2007; SANTOS, 2006), ou no ambiente (CORAZZA-NUNES et al., 2007; PEDRANCINI et al., 2007).

Outro aspeto a salientar é que a compra do OGM depende também de outros fatores, como o preço, o gosto, conforto ou a estética do produto, o que está de acordo com um dos resultados do estudo de Klop e Severiens (2007), quando referem que a opinião em relação à biotecnologia depende de fatores cognitivos, afetivos e comportamentais.

Com o intuito de aprofundar as opiniões dos alunos em relação aos OGMs, foi apresentado, aos alunos, um diálogo entre cinco personagens (Manuel, Rita, Mariana, Pedro e Rui), cada uma delas com uma opinião diferente em relação aos OGMs. Os alunos deveriam assinalar qual a personagem com quem se identificavam mais.

Na Tabela 8, apresentamos esses resultados. 
Da análise da Tabela 8, que apresentamos em seguida, constata-se que a personagem que evoca fatores de natureza ética foi a mais referida, seguida da personagem que defende que os OGMs comportam riscos. As menos referidas foram, por ordem decrescente: a que atribuiu vantagens aos OGMs, a que considerou os OGMs equivalentes aos não-GM, ou que assume o seu desconhecimento em relação a estes organismos.

Tabela 8. Opiniões dos alunos em relação às implicações dos OGMs e sua relação com as personagens do texto apresentado no questionário

\begin{tabular}{lrr}
\hline \multicolumn{1}{c}{ Resposta } & \multicolumn{1}{c}{ Alunos (n= 171) } \\
\cline { 2 - 3 } & $\mathbf{f}$ & \% \\
\hline Manuel (desconhecia que os OGMs podem trazer benefícios às populações) & 4 & 2,3 \\
$\begin{array}{l}\text { Rita (os OGM podem trazer vantagens em diferentes áreas, como a saúde, o } \\
\text { ambiente ou atividades económicas) }\end{array}$ & 27 \\
Mariana (os OGMs comportam riscos para a saúde e o ambiente) & 59 & 34,5 \\
$\begin{array}{l}\text { Pedro (os OGMs resultam de interferência intencional do Homem na natureza } \\
\text { e, como tal, devem ser recusados) }\end{array}$ & 60 & 35,1 \\
$\begin{array}{l}\text { Rui (não há diferenças importantes entre organismos GM e não-GM, pelo } \\
\text { que o fator económico é o mais determinante na escolha) }\end{array}$ & 21 \\
\hline
\end{tabular}

Fonte: Elaborado pelos autores.

Na Tabela 9, apresentamos a fundamentação dos alunos que se identificaram com a personagem 'Pedro', ou seja 'os OGMs resultam de interferência intencional do Homem na natureza e, como tal, devem ser recusados’. Esta personagem foi a mais referida pelos alunos.

Tabela 9. Fundamentação dos alunos que se identificaram com a personagem 'Pedro' - 'os OGMs resultam de interferência intencional do Homem na natureza e, como tal, devem ser recusados'

\begin{tabular}{lrr}
\hline \multicolumn{1}{c}{ Categoria } & \multicolumn{2}{c}{ Alunos $(\mathbf{n = 6 0 )}$} \\
\cline { 2 - 3 } Não concordo com a interferência do Homem na natureza & $\mathbf{f}$ & $\mathbf{\%}$ \\
É necessária mais informação sobre os OGMs & 46 & 76,7 \\
A opinião da personagem é idêntica à minha & 5 & 8,3 \\
Os OGMs podem trazer riscos para o ambiente & 3 & 5,0 \\
Não tenho interesse no assunto & 2 & 3,3 \\
Não responde & 1 & 1,7 \\
\end{tabular}

Fonte: Elaborado pelos autores.

Os dados da Tabela 9 demonstram que mais de dois terços dos que se identificaram com a personagem 'Pedro', deram respostas da categoria 'Não concordo com a interferência do Homem na natureza', o que remete para aspetos da natureza ética, os quais foram pouco invocados nas questões da compra do óleo com soja GM, ou da t-shirt com algodão GM.

Das restantes fundamentações, salientamos o facto de, por um lado, haver, por vezes, incoerência entre a fundamentação e a opinião da personagem, nomeadamente quando os alunos dão respostas das categorias 'ainda não se conhece tudo sobre os OGMs' ou 'os 
OGMs podem trazer riscos para o ambiente', e, por outro lado, de as fundamentações serem demasiado vagas e generalistas.

$\mathrm{Na}$ Tabela 10, apresentamos a fundamentação dos alunos que se identificaram com a personagem 'Mariana', cuja opinião era: 'os OGMs comportam riscos para a saúde e o ambiente'. Esta personagem foi a segunda mais referida pelos alunos

Tabela 10. Fundamentação dos alunos que se identificaram com a personagem 'Mariana' - 'os OGMs comportam riscos para a saúde e o ambiente'

\begin{tabular}{lrr}
\hline \multicolumn{1}{c}{ Categoria } & \multicolumn{2}{c}{ Alunos $(\mathbf{n = 5 9 )}$} \\
\cline { 2 - 3 } & $\mathbf{f}$ & \% \\
\hline Os OGMs têm riscos & 30 & 50,8 \\
Os OGM têm vantagens e inconvenientes & 19 & 32,2 \\
A opinião da personagem é idêntica à minha & 4 & 6,8 \\
Não tenho interesse no assunto & 1 & 1,7 \\
Os OGMs podem atenuar a fome no mundo & 1 & 1,7 \\
Os OGMs podem ser bons para a saúde e para o ambiente & 1 & 1,7 \\
Não responde & 3 & 5,1 \\
\hline
\end{tabular}

Fonte: Elaborado pelos autores.

Da análise da Tabela 10 e quanto aos alunos que se identificaram com a personagem 'Mariana', verificamos que a categoria mais frequente é a de que os OGMs têm riscos. Dos trinta alunos que deram este tipo de resposta, 12 alunos referiram riscos a nível da saúde e do ambiente, cinco referiram apenas riscos a nível de saúde, um aluno referiu, exclusivamente, riscos a nível ambiental, 12 alunos referiram apenas que a utilização dos OGMs traz riscos.

Nas restantes categorias de resposta, apenas realçamos que, na segunda categoria de resposta mais frequente, $32,2 \%$ dos alunos referem que os OGMs têm vantagens e inconvenientes, sem que especifiquem quais, o que é um contrassenso em relação à opinião da personagem. As restantes categorias de resposta, ou são demasiado vagas, ou não estão diretamente relacionadas com a situação apresentada.

$\mathrm{Na}$ Tabela 11, apresentamos a fundamentação dos alunos que se identificaram com a personagem 'Rita', a qual defendia que 'os OGM podem trazer vantagens em diferentes áreas, como a saúde, o ambiente ou atividades económicas'. Esta personagem foi a terceira mais referida pelos alunos.

Tabela 11. Fundamentação dos alunos que se identificaram com a personagem 'Rita' - 'os OGM podem trazer vantagens em diferentes áreas, como a saúde, o ambiente ou atividades económicas'

\begin{tabular}{lrr}
\hline & \multicolumn{2}{c}{ Alunos (n= 27) } \\
\cline { 2 - 3 } \multicolumn{1}{c}{ Categoria } & $\mathbf{f}$ & \% \\
\hline Os OGMs têm muitas vantagens & 17 & 63,0 \\
A opinião da personagem é idêntica à minha & 5 & 18,5 \\
Os OGMs podem atenuar a fome no mundo & 2 & 7,4 \\
Fundamentação não relacionada & 1 & 3,7 \\
Não responde & 2 & 7,4 \\
\hline
\end{tabular}

Fonte: Elaborado pelos autores. 
Analisando a Tabela 11, relativa aos 27 alunos que se identificaram com a personagem 'Rita', verifica-se que a categoria de resposta mais frequente é a de que os OGMs têm muitas vantagens, sem que se especifiquem quais. As restantes categorias de resposta ou são fundamentações vagas ou não estão diretamente relacionadas com a situação apresentada.

$\mathrm{Na}$ Tabela 12, apresentamos a fundamentação dos alunos que se identificaram com a personagem 'Rui', cuja opinião é 'não há diferenças importantes entre organismos GM e nãoGM, pelo que o fator económico é o mais determinante na escolha’. Esta personagem foi a quarta mais referida pelos alunos

Tabela 12. Fundamentação dos alunos que se identificaram com a personagem 'Rui' - 'não há diferenças importantes entre organismos GM e não-GM, pelo que o fator económico é o mais determinante na escolha'

\begin{tabular}{lcc}
\hline & \multicolumn{2}{c}{ Alunos $(\mathbf{n}=\mathbf{2 1})$} \\
\cline { 2 - 3 } \multicolumn{1}{c}{ Categoria } & $\mathbf{f}$ & $\%$ \\
\hline A opinião da personagem é idêntica à minha & 6 & 28,6 \\
O importante é o preço do produto final & 6 & 28,6 \\
Não tenho interesse no assunto & 2 & 9,5 \\
Os OGMs são equivalentes aos não-GM & 2 & 9,5 \\
O importante é a qualidade do produto final & 2 & 9,5 \\
Fundamentação não relacionada & 1 & 4,8 \\
Não responde & 2 & 9,5 \\
\hline
\end{tabular}

Fonte: Elaborado pelos autores.

Quanto à Tabela 12, onde se apresentam as fundamentações dadas pelos alunos que se identificaram com a personagem 'Rui', verificamos que as mesmas são vagas ou se limitam a repetir a opinião da personagem.

Em relação à personagem 'Manuel', apenas quatro alunos se identificaram com a sua opinião, ou seja, 'desconhecia que os OGMs podem trazer benefícios às populações'. Dois destes alunos disseram apenas que a opinião da personagem era idêntica à sua; um aluno apenas referiu que os OGMs têm vantagens; um aluno disse não ter interesse no assunto.

Numa síntese sobre as opiniões dos alunos em relação aos OGMs, verifica-se que é frequente que a opinião do aluno varie consoante as circunstâncias e o tipo de OGM, pois as respostas dadas no caso da compra do óleo de soja GM, da compra da t-shirt com algodão GM ou da personagem escolhida nem sempre foram semelhantes.

Também se nota que a fundamentação apresentada pelos alunos é, de uma forma geral, vaga, genérica e, por vezes, contraditória com a resposta dada. Isto vai ao encontro de um dos resultados dos estudos de Corazza-Nunes et al. (2007), de Pedrancini et al. (2007), quando dizem que os alunos fundamentam de forma vaga a opinião que têm sobre os OGMs.

\section{Conclusões}

Dos resultados obtidos em relação às concepções e opiniões dos alunos envolvidos no estudo sobre os OGMs, podemos tirar várias conclusões. 
Quase todos os alunos reconheceram ter ouvido falar de OGMs e que tal aconteceu, sobretudo, nas aulas, tendo o manual escolar sido um dos veículos dessa informação. Com menor frequência, alguns alunos referiram ter ouvido falar em OGMs noutros contextos, entre os quais a internet e diversos meios audiovisuais. O facto de o número de respostas que referem estes meios ser bastante inferior ao das respostas 'aulas' ou 'manual', evidencia que o manual escolar continua a ser o suporte de aprendizagem mais comum no ensino das ciências e o mais relevante para professores e alunos, tal como refere Santos (2001).

Apenas cerca de metade dos alunos apresentou o conceito de OGM cientificamente correto, enquanto $12,2 \%$ dos alunos deram respostas que sugerem aproximação do conceito de OGM ao de transgénico, e 5,3\% dos alunos consideram que os OGMs são clones.

Quanto aos exemplos de OGMs dados pelos alunos, eles são muito variados e os mais referidos constam dos manuais escolares. O maior número de exemplos de OGMs referidos pelos alunos é de plantas, sendo as mais frequentes: o milho, o 'arroz dourado' e o tomate.

A maioria dos alunos não rejeita os OGMs apresentados, mas muitos demonstraram ter reservas na sua utilização e estão mais receptivos à utilização de OGMs de tipo não alimentar do que aos OGMs de tipo alimentar.

Os argumentos utilizados pelos alunos para comprar, ou não, produtos com OGMs são vários, sendo o argumento mais frequente a sua segurança e as possíveis implicações dos OGMs, sobretudo para a saúde.

Em relação à fundamentação de compra/rejeição de OGMs, a utilização de argumentos que não estão diretamente relacionados com estes organismos, como o aspeto ou o sabor do produto, é mais frequente no caso da compra de um OGM de tipo não alimentar (t-shirt) do que na compra de um OGM de tipo alimentar (óleo alimentar). A frequência desta categoria de resposta vai de encontro a um dos resultados do estudo de Klop e Severiens (2007), quando referem que a opinião sobre a biotecnologia depende de fatores cognitivos, afetivos e comportamentais.

Ainda em relação à fundamentação de compra/rejeição de OGMs, verifica-se, por parte de muitos alunos, a existência de explicações vagas, generalistas e pouco consistentes. Este aspeto está de acordo com vários estudos (CORAZZA-NUNES et al., 2007; PEDRANCINI et al., 2007; PEDRANCINI et al., 2008), e foi acentuado quando se pediu aos alunos que se identificassem com a opinião de uma das personagens do diálogo sobre OGMs.

As opiniões dos alunos em relação aos OGMs mudam, por vezes, consoante a circunstância e o OGM considerados. Para além disso, há, por vezes, contradições entre a opinião apresentada e a respetiva fundamentação.

Quanto às implicações deste estudo, consideramos que a falta de reflexão e de discussão sobre OGMs demonstrada, salienta necessidade de se garantir mais espaço para a discussão de temas sociocientíficos nas aulas de ciências. Também o facto de os alunos concluírem o Ensino Básico com ideias vagas e que nem sempre estão corretas, torna importante que haja momentos de aprendizagem ao longo da vida e que os cidadãos sejam dotados de ferramentas, durante a sua passagem pela escola, que lhes permitam analisar criticamente a informação que vão recebendo de terceiros ou que lhes chega por meio da comunicação social.

Deste modo, pode ser importante, por um lado, a realização de investigações sobre a problemática dos OGMs, com público-alvo de outros níveis de ensino e/ou por intermé- 
dio de outra técnica de recolha de dados, capazes de complementar este estudo, mas também investigações sobre outros assuntos de natureza sociocientífica, como o desenvolvimento sustentável ou as radiações a que estamos sujeitos (por exemplo, através do uso do telemóvel).

\section{Referências}

BARDIN, L. Análise de conteúdo. Lisboa: Edições 70, 2004.

BORÉM, A.; SANTOS, R.; BOWEN, D. Understanding biotechnology. New Jersey: Prentice Hall, 2003.

CACHAPUZ, A.; PRAIA, J.; JORGE, M. Da educação em ciência às orientações para o das ciências: um repensar epistemológico. Ciência \& Educação, Bauru, v. 10, n. 3, p. 363-381, 2004.

CHERN, W. S.; RICKERTSEN, K. Consumer acceptance of GMO: survey results from Japan, Norway, Taiwan and the United States. Taiwanese Agricultural Economic Review, Taiwan, v. 7, n. 1, p. 1-28, 2001.

CORAZZA-NUNES, M. et al. O que conhecem os estudantes do ensino médio e ensino superior sobre transgênicos. In: ENCONTRO NACIONAL DE PESQUISA EM EDUCAÇÃO EM CIÊNCIAS, 6., 2007, Florianópolis. Anais... [S. 1.]: Associação Brasileira de Pesquisa em Educação em Ciências, 2007.

DAWSON, V. An exploration of high school (12-17 year old) students' understandings of, and attitudes towards biotechnology processes. Research in Science Education, Malden, v. 37, n. 1, p. 59-73, 2007.

DE KETELE, J.; ROEGIERS, X. Metodologia da recolha de dados: fundamentos dos métodos de observações, de questionários, de entrevistas e de estudo de documentos. Lisboa: Instituto Piaget, 1993.

FERNANDEZ-CORNEJO, J.; CASWELL, M. The first decade of genetically engineered crops in the United States. Washington: United States Department of Agriculture, 2006. (Economic Information Bulletin, 11). Disponível em: <http://www.ers.usda.gov/ersDownloadHandler. ashx?file=/media/255908/eib11_1_.pdf $>$. Acesso em: 12 maio 2014.

FIRMINO, M. Biotecnologia: estudo exploratório das percepções e atitudes de professores e estudantes. 2007. 107 f. Dissertação (Mestrado em Biologia para o Ensino) - Faculdade de Ciências, Universidade do Porto, Porto, 2007.

FUNDACIÓN COTEC. Biotecnologia y alimentacion. Madrid: COTEC, 2006.

GALL, M., GALL, J.; BORG, W. Educational research: an introduction. Boston: Pearson Education, 2003.

JAMES, C. Global status of commercialized biotech/GM crops: 2008. New York: International Service for the Acquisition of Agri-Biotech Applications, 2008. (ISAAA brief, 39). Disponível em: $<$ http://www.isaaa.org/resources/publications/briefs/39/download/isaaa-brief-39-2008.pdf>. Acesso em: 12 maio 2014.

KLOP, T.; SEVERIENS, S. An exploration of attitudes towards modern biotechnology: a study among dutch secondary school students. International Journal of Science Education, Abingdon, v. 29, n. 5, p. 663-679, 2007. 
MATTHEWS, M. Science, worldviews and education: an introduction. Science Education, New York, v. 18, p. 641-666, 2009.

MCMILLAN, J.; SCHUMACHER, S. Research in education: evidence: based inquiry. Boston: Pearson Education, 2006.

PEDRANCINI, V. et al. Ensino e aprendizagem de biologia no ensino médio e a apropriação do saber científico e biotecnológico. Revista Electrónica de Enseñanza de las Ciencias, Vigo, v. 6, n. 2 , p. 299-309, 2007.

. Saber científico e conhecimento espontâneo: opiniões de estudantes do ensino médio sobre transgênicos. Ciência \& Educação, Bauru, v. 14, n. 1, p. 135-146, 2008.

PORTUGAL. Ministério da Educação. Departamento da Educação Básica. Currículo nacional do ensino básico: competências essenciais. Lisboa, 2001a.

. Ministério da Educação. Departamento da Educação Básica. Orientações curriculares de ciências físicas e naturais. Lisboa, 2001b.

PROKOP, P. et al. Slovakian students' knowledge of and attitudes toward biotechnology.

International Journal of Science Education, Abingdon, v. 29, n. 7, p. 895-907, 2007.

REIS, P. A escola e as controvérsias sociocientíficas: perspectivas de alunos e de professores. Lisboa: Escolar Editora, 2008.

SÁEZ, M.; NIÑO, A.; CARRETERO, A. Matching society values: students’ views of biotechnology. International Journal of Science Education, Abingdon, v. 30, n. 2, p. 167-183, 2008.

SANTOS, M. A cidadania na "voz" dos manuais escolares: o que temos? o que queremos? Lisboa: Livros Horizonte, 2001.

SANTOS, E. Ensino de ciências e literacia científica: o caso dos organismos geneticamente modificados. 2006. 163 f. Dissertação (Mestrado em Comunicação e Educação em Ciência) - Secção Autónoma de Ciências Sociais, Políticas e Jurídicas, Universidade de Aveiro, Aveiro, 2006.

SEHNAL, F.; DROBNÍK, J. White book genetically modified crops: scientific opinion of czech researchers working with GMO. Praga: Biology Centre of the Academy of Sciences of the Czech Republic, 2009.

USAK, M. et al. Biotechnology education - high school and university students' knowledge and attitudes regarding biotechnology: a turkish experience. Biochemistry and Molecular Biology Education, Malden, v. 37, n. 2, p. 123-130, 2009.

VARZAKAS, T.; ARVANITOYANNIS, I.; BALTAS, H. The politics and science behind GMO acceptance. Critical Reviews in Food Science and Nutrition, London, v. 47, n.4, p. 335- 361, 2007.

WINHAM, G. The GMO panel: applications of WTO law to trade in agricultural biotech products. Journal of European Integration, Maastricht, v. 31, n. 3, p. 409-429, 2009.

WYNNE, B. Creating public alienation: expert cultures of risk and ethics on gmos'. Science as Culture, London, v. 10, n. 4, p. 445-481, 2001. 